\title{
Convective Heat Transfer from High- temperature Air Inside a Tube
}

HERBERT E. ZELLNIK and STUART W. CHURCHILL

Univorsity of Miehigan, Ann Arbor, Miehigon

Local rates of convective heat transfer from air at high temperature to a cold wall were measured in the inlet region of a circular tube. Air entered the tube with a fiat velocity and temperature profile at temperatures from $480^{\circ}$ to $2,000^{\circ} \mathrm{F}$. and flow rates corresponding to Reynolds numbers from 4,500 to 22,500 . The inner surface of the 1.0 -in. I.D. tube was maintained at approximately $100^{\circ} \mathrm{F}$. by water cooling. Local rates of heat transfer were determined at $1.5,4,7$, and 10 tube diameters from the entrance by measuring the radial temperature profile in thermally isolated, annular sections of the tube wall.

The local rate data for all gas temperatures are well represented by previous correlations for small temperature differences if the gas properties are evaluated at the bulk temperature rather than at the film temperature. The data agree well with the data of previous investigators wherever the experimental ranges overlap.

Convective heat transfer to and from gases flowing in tubes has been investigated extensively, but primarily in long tubes at ambient conditions. The generally accepted correlations are therefore subject to such. limitations. Current interest in the extension of the temperature range of many engineering operations and in compact heat exchangers suggests the experimental extension and the reevaluation of these correlations.

Excellent summaries of previous work may be found in MaAdams (1) and Groeber, et al. (2), The most definitive data for the local rate of heat transfer in the inlet region are those of Boelter, et al. (3). The analytical results of Deissler (4) based upon an empirical equation for the eddy diffusivity agree well with these data (3). The only extensive data for convection in tubes at extreme temperatures are those of Humble, et al. (5), on air heated at tube-wall temperatures up to $2,950^{\circ} \mathrm{F}$. Limited data were also obtained for heat extraction at air temperatures up to $1,040^{\circ} \mathrm{F}$. The length of the tube was varied but in increments too long for the derivation of local rates. The data deviated significantly from lowtemperature correlations and for theoretically proposed equations for large temperature differences $(6)$.

This investigation was undertaken to evaluate the effect of increasing air temperatures on the local rate of heat transfer in the inlet region. A uniform wall temperature, turbulent flow, and a flat velocity profile at the inlet were chosen as boundary conditions.

\section{EXPERIMENTAL APPARATUS AND PROCEDURE}

The apparatus was designed to provide gas at temperatures up to $2,500^{\circ} \mathrm{F}$. and flow rates up to 25 std. cu. ft./min. and to measure local rates of heat transfer to a cold wall in the entrance section of a circular

H. E. Zellnik is at present with Union Carbide Nuclear Company, New York, New York.

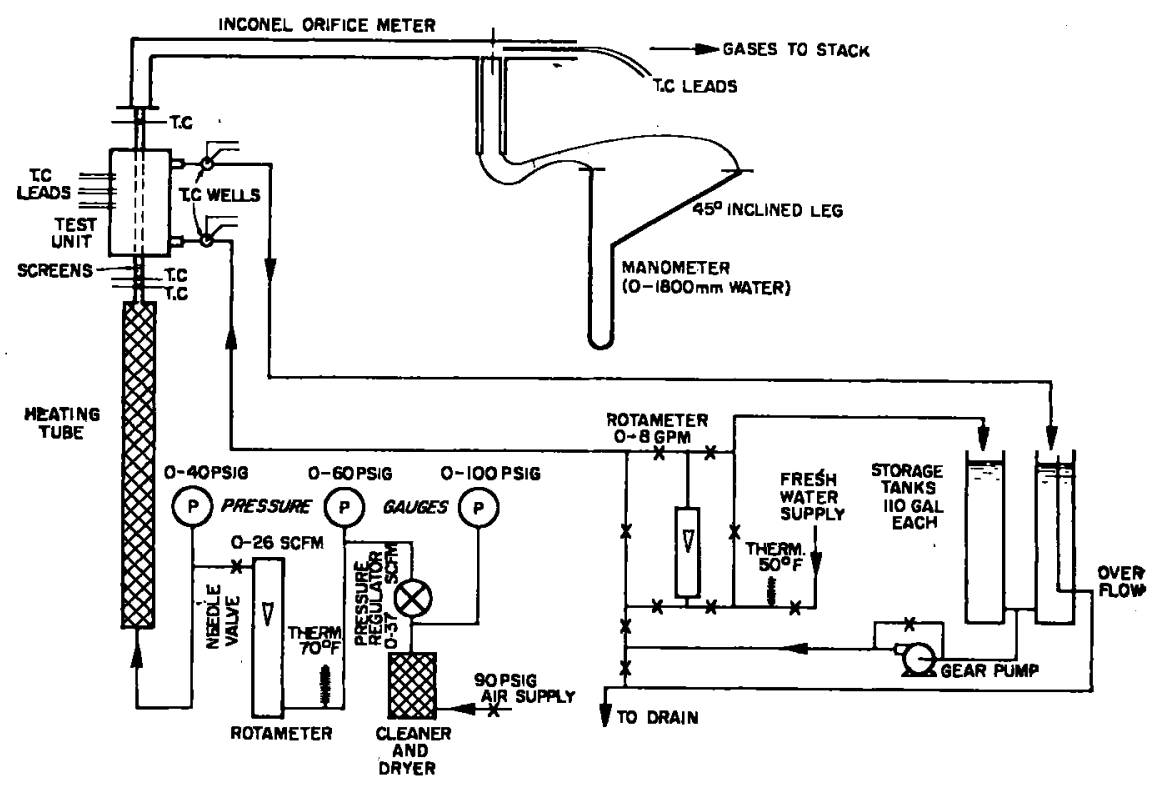

7 Fig. 1. Schematic diagram of equipment.

Fig. 2. Detail of adiabatic sections and top furnace assembly

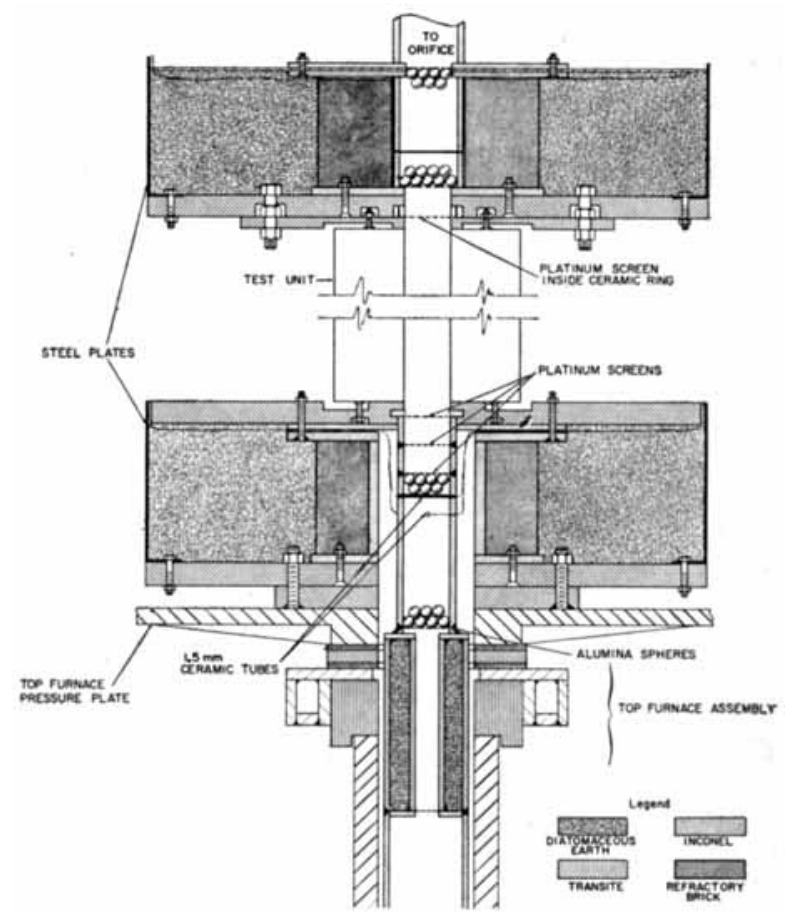


tube. Compressed air was passed through a cleaner and dehumidifier, then through a rotameter at regulated pressure, and was heated in passage through a packed tube in an electric resistance furnace. The temperature of the air entering the test section was measured in a packed adiabatic tube at the furnace outlet. Hot-wire-anemometer measurements showed that a negligible intensity of turbulence and a flat velocity profile at the inlet to the test section were established by three 52-mesh platinum screens when the air was not heated. It is assumed that similar conditions existed in the heated gas at the same Reynolds number. The test section consisted of a 1.0-in. I.D. by 1.8-in. O.D. by 11.25-in.-long water-coo'ed Inconel tube. The air leaving the test section passed through another adiabatic packed tube in which the exit temperature was measured and then through an orifice. The orifice was installed because of leakage of gas in passage through the furnace. A sketch of the apparatus is shown in Figure 1 and details of the adiabatic sections appear in Figure 2.

The temperatures of the gas and packing were assumed to be equal near the outlet and inlet respectively of the inlet and outlet packed adiabatic tubes. The temperature of the packing, which consisted of 1/4-in. alumina spheres, was measured with buttwelded 28 gauge Chromel-Alumel thermocouples in a singly perforated ceramic tube as shown. Since the tube can "see" only packing at essentially the same temperature, the error due to radiation is negligible. The theoretical and experimental basis for this method of determining the gas temperature is discussed in further detail in reference 7 .

Details of the test section are indicated in Figure 3. Thirty-six-gauge, coated, buttwelded Chromel-constantan thermocouples were induction-welded at the bottom of 20-mil holes at three radii in each of four thermally isolated annular sectors of the Inconel tube. The thermocouple junctions were precisely located at the end of the experimental work by slicing the tube near the couples and $X$-raying. The midpoints of the annular sectors were $1.5,4,7$, and 10 in. from the inlet of the heated tube. The insulating slots and the holes were filled with a silicon resin after insertion of the thermocouples, and the test object was baked at $500^{\circ} \mathrm{F}$. The tube was enclosed in a brass shell for cooling and was insulated from the adjacent adiabatic sestions by transite sheets and asbestos gaskets. Cooling-water temperatures were measured with Chromel-constantan thermocouples in wells in the inlet and outlet piping, and the flow rate was measured with a rotameter.

Runs were made at gas inlet temperatures of approximately 500,1,000, 1,500, and $2,000^{\circ} \mathrm{F}$, and at flow rates corresponding to bulk Reynolds numbers of approximately $5,000,7,500,10,000,12,000,15,000$, and 20,000 ; flow rates corresponding to a Reynolds number of 20,000 at $1,500^{\circ} \mathrm{F}$. and of 15,000 at $2,000^{\circ} \mathrm{F}$. were not attainable owing to limitations of the pressure-regulating and flow-measuring instruments. Surface temperatures ranged from 73 to $208^{\circ} \mathrm{F}$. from run to run but were uniform within $\pm 2 \%$ of the absolute temperature from station to station. Only illustrative dats are presented herein. The detailed data are presented in both graphical and tabular form in reference 8 .

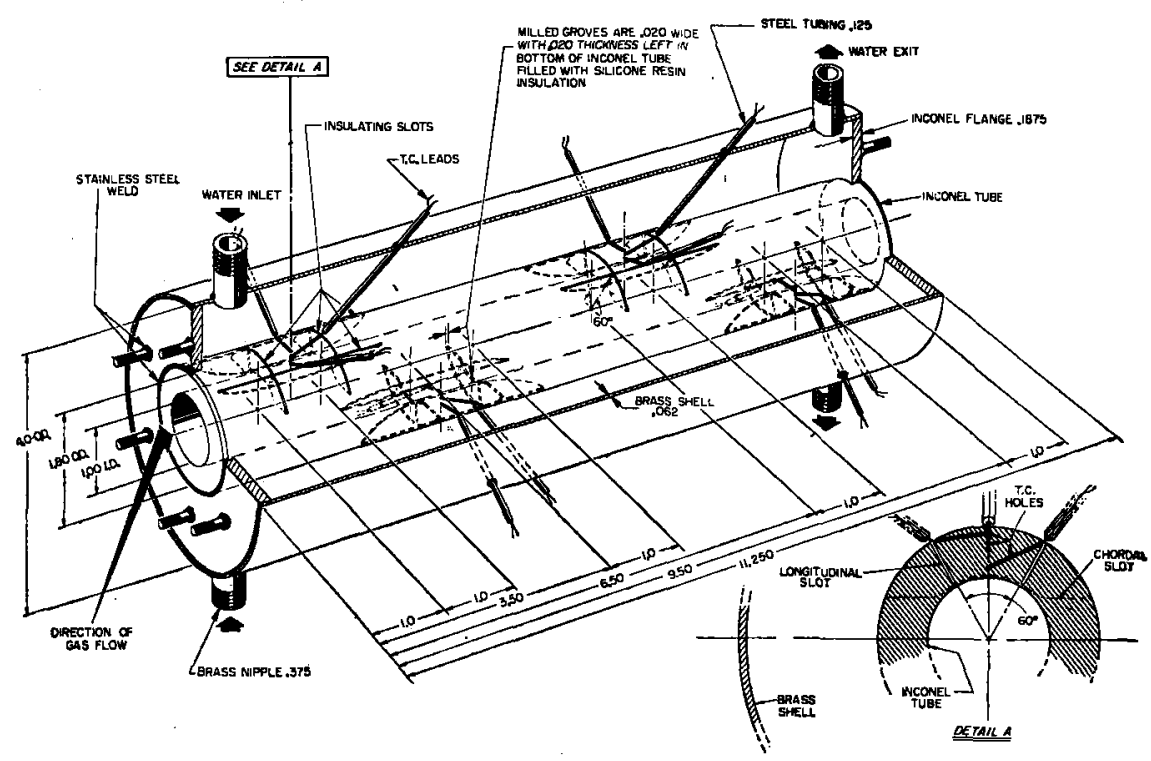

Fig. 3. Detail of test section.
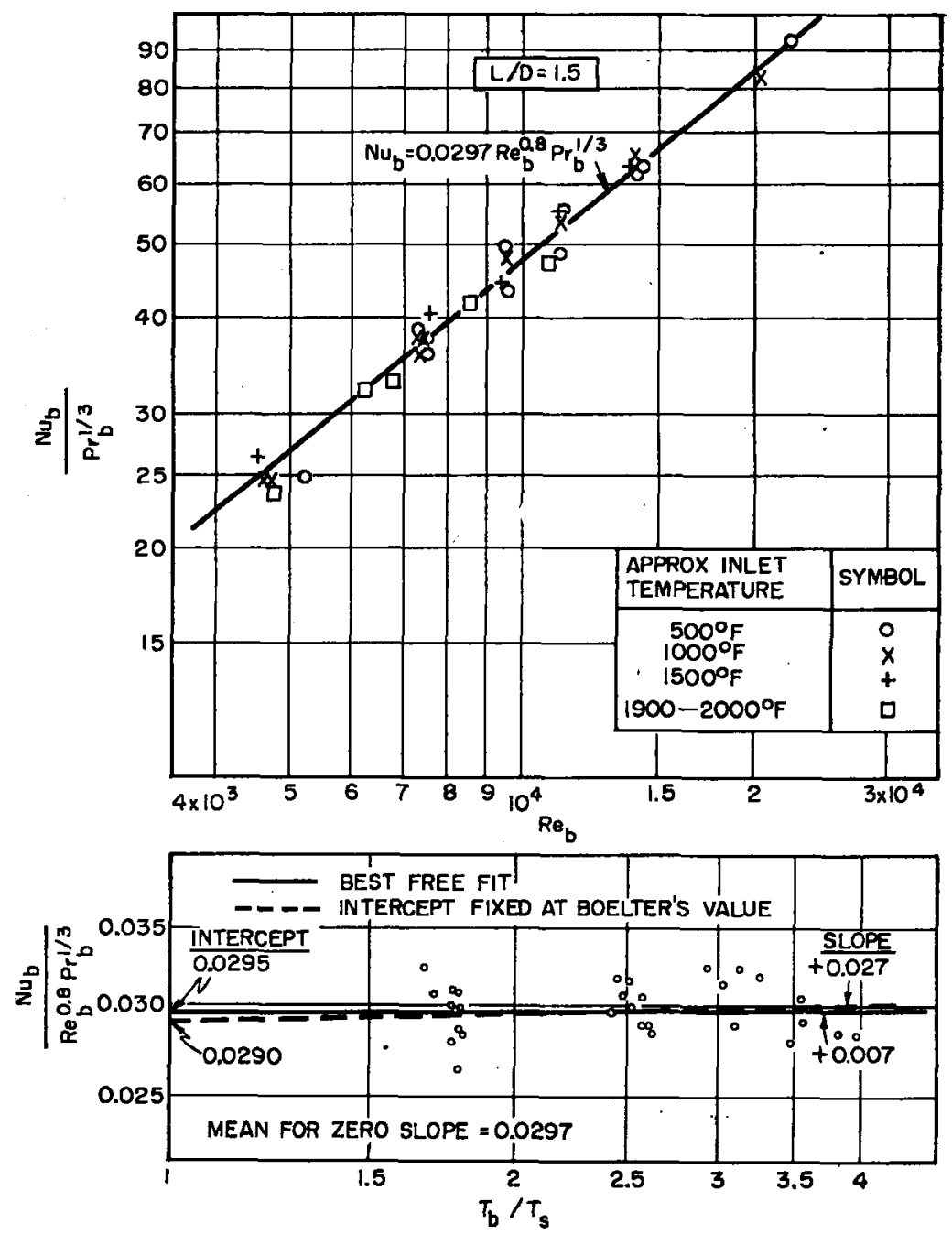

Fig. 4. Correlation of heat transfer data for $L / D=1.5$; properties evaluated at bulk temperature. 
DETERMHNATION OF THE RATE FROM THE DATA

For steady state, constant conductivity, and negligible angular and longitudinal gradients in a hollow cylinder the equation for conduction reduces to

$$
\frac{1}{r} \frac{d}{d r}\left(r \frac{d T}{d r}\right)=0
$$

and a solution can be written in terms of known temperatures at any two points $\left(T_{1}, r_{1}\right)$ and $\left(T_{2}, r_{2}\right)$

$$
\frac{T-T_{1}}{T_{2}-T_{1}}=\frac{\ln r / r_{1}}{\ln r_{2} / r_{1}}
$$

The surface temperature can be calculated from Equation (2) or found graphically by extrapolation of a straight line through two or more points on a plot of $T$ vs. $\ln r$.

The heat flux through the wall is found in terms of two of the measured wall temperatures or in terms of the surface temperatures determined from all three measured temperatures:

$q_{s}=\frac{k_{m}}{r_{s}} \frac{\left(T_{2}-T_{1}\right)}{\ln r_{1} / r_{2}}=\frac{k_{m}}{r_{s}} \frac{\left(T_{s}-T_{o}\right)}{\ln r_{o} / r_{s}}$

The convective heat transfer coefficient is obtained by.subtracting the radiant flux to the wall from the measured flux

$$
h=\frac{q_{s}-q_{r}}{T_{b}-T_{s}}
$$

The radiant flux between the platinum screens at the ends of the test section and points on the surface was calculated by use of the interchange factors computed by Hamilton and Morgan (9). This correction reached a maximum of $8 \%$ of the total flux at a gas temperature of $2,000^{\circ} \mathrm{F}$. and an $L / D$ of 1.5 .

The gas temperature at any $L / D$ could be computed from either the inlet temperature or outlet temperature and the integrated convective flux to the wall. However, the inlet and outlet thermocouples demonstrated some inconsistency, which is to be expected at the conditions at which they were used. Consequently a linear variation of gas temperature between the measured temperatures was assumed to minimize the uncertainty introduced by an error in either thermocouple reading. The maximum uncertainty introduced in the heat transfer coefficients by this decision was $2 \%$.

\section{CORRELATION OF RATE DATA}

The experimental data for each of the four stations were correlated separately in terms of the empirical equation

$\frac{h D}{k}=A\left(\frac{C_{p} \mu}{k}\right)^{1 / 3}\left(\frac{D G}{\mu}\right)^{0.8}\left(\frac{T_{b}}{T_{s}}\right)^{m}$

The form of Equation (5) and the expo- nents for the Prandtl and Reynolds numbers were chosen on the basis of previous investigations for small temperature differences. The Prandtl number was not varied significantly in this investigation and, as will be shown, the effect of Reynolds number over the fivefold range of this investigation appears to be adequately represented by the 0.8 power.

The representation of the data by Equation (5) was investigated with the viscosity and thermal conductivity evaluated at the bulk, film, and surface temperatures. Since Keenan and Kay (10) give values for both the thermal conductivity and the viscosity of air, these values were used rather than the more recent values of Hilsenrath (11) for the viscosity, which agree up to $800^{\circ} \mathrm{F}$. but are $2 \%$ lower at $2,000^{\circ} \mathrm{F}$. Since Hilsenrath reported a variation in $\left(C_{p} \mu / k\right)^{1 / 3}$ only from 0.879 to 0.891 for the entire range of this experimental work, a mean value of 0.885 was used. Evaluation of the properties at the bulk temperature was found to give the best fit.

Specifically Equation (5) was rearranged in the form

$$
\begin{aligned}
& \ln \frac{(h D / k)}{\left(C_{p} \mu / k\right)^{1 / 3}(D G / \mu)^{0.8}} \\
& \quad=\ln A+m \ln \left(\frac{T_{b}}{T_{\mathrm{a}}}\right)
\end{aligned}
$$

and $A$ and/or $m$ were determined by least squares for three cases:

1. The best free fit, equivalent to the best straight line through a plot of $\log (h D / k) /\left(C_{p} \mu / k\right)^{1 / 3}(D G / \mu)^{0.8}$ vs. $\log$ $\left(T_{b} / T_{s}\right)$

2. Fixed $A$. The best value of $m$ was found with $A$ equal to $0.023\left(h / h_{\infty}\right)$. The ratio of the local coefficient to the asymptotic coefficient for large $L / D$ was computed from the results of Boelter, et al. (3) for a flat velocity profile at the inlet and is included in Table 1. This representation is equivalent to the best straight line through the chosen value of $A$ on the previously discussed plot and forces extrapolation of the correlation to the low-temperature results of Boelter as $T_{b} / T_{a}$ approaches unity.

3. Zero exponent for temperature ratio. The best value of $A$ was found for $m=0$. This is equivalent to the best straight line of zero slope on the previously discussed plot.

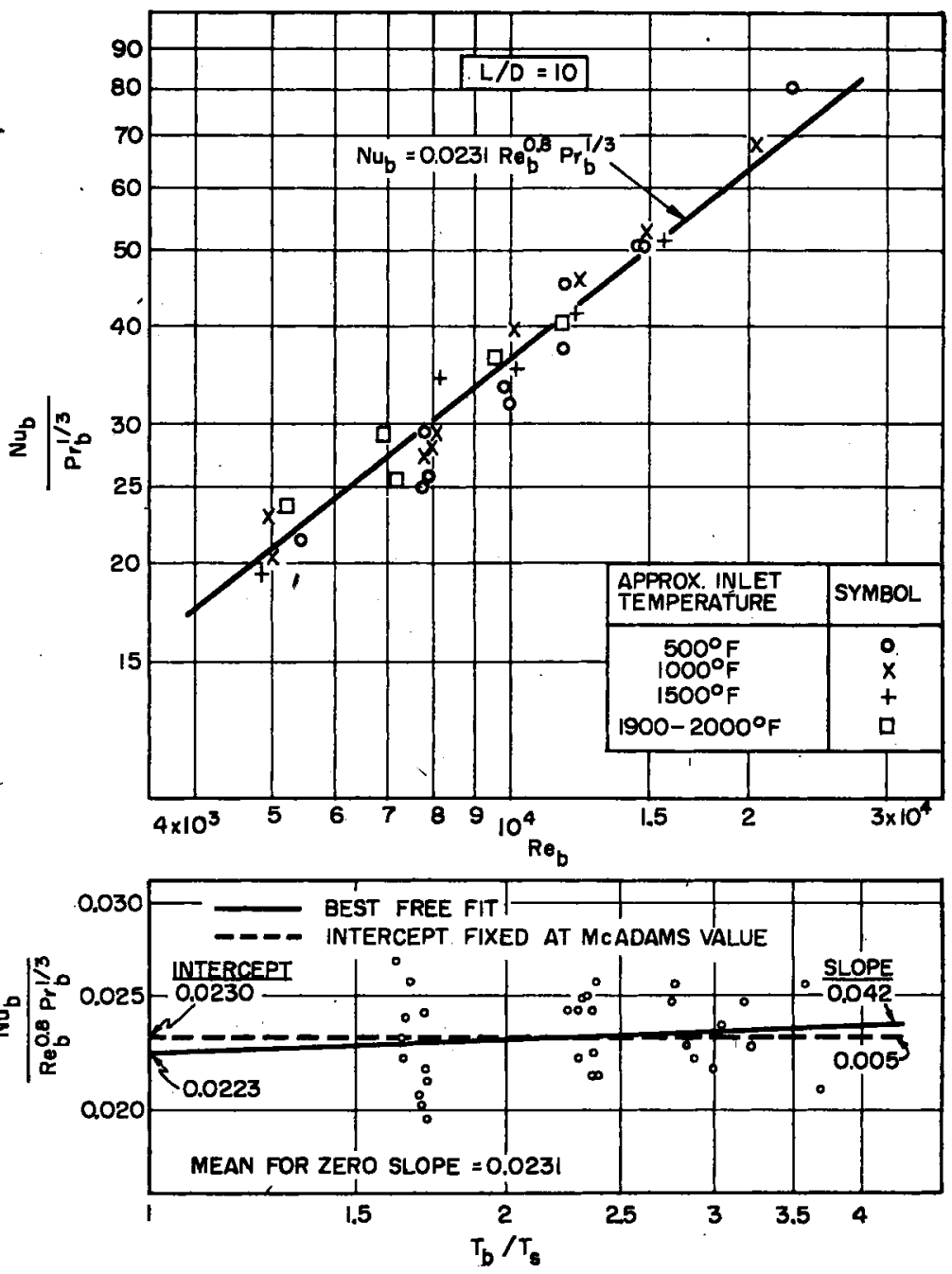

Fig. 5. Correlation of heat transfer data for $L / D=10$; properties evaluated at bulk temperature. 
The correlation procedure is illustrated for $L / D$ of 1.5 and 10.0 in the lower graph in Figures 4 and 5 and the results are summarized for all four stations in Table 1. The standard deviations in $\log (h D / k) /\left(C_{p} \mu / k\right)^{1 / 3}(D G / \mu)^{0.8}$ are not significantly greater for the third case than for the free fit. Therefore the correlation

$$
\frac{h D}{k_{b}}=A\left(\frac{C_{p} \mu}{k}\right)^{1 / 3}\left(\frac{D G}{\mu_{b}}\right)^{0.8}
$$

with $A$ given under case 3 in Table 1 is recommended in terms of simplicity. The limited results of Humble, et al, (5) for cooling air were also reported to show no dependence on temperature when expressed in terms of bulk temperature.

The lowest graph of Figures 4 and 5 exaggerates the deviations. The upper graph indicates the representation of the data for $L / D$ of 1.5 and 10.0 by Equation (7) in more customary form. The data are plotted in terms of the local bulk temperature at $L / D$ of 1.5 and 10.0 respectively but for simplicity are coded in terms of the inlet temperature $(L / D=0)$. The scatter with respect to gas temperature appears to be random and the arbitrary choice of an exponent of 0.8 for the Reynolds number appears satisfactory. The representations obtained for the other two intermediate stations are quite comparable to the representation in Figures 4 and 5 and therefore are not reproduced here.

\section{DISCUSSION}

That the correlation is independent of the surface temperature is probably fortuitous. The data of this investigation and that of Humble, et al. were obtained at nearly ambient and constant surface temperatures. Correlation of future data for a high fixed bulk temperature and a variable surface temperature will probably require explicit inclusion of the surface temperature or of properties dependent upon the surface temperature. The present correlation should not be inferred to hold for these conditions.

The constants $A$ and $m$ for a free fit and $m$ for fixed $A$ were also evaluated with the properties evaluated at the film and surface temperature. Some of the results for $L / D$ of 1.5 and 10.0 are compared in Table 2. The dependence on the temperature ratio is seen to increase as the properties are evaluated at successively lower temperatures.

The viscosity of air is approximately proportional to $T^{0.68}$ and the thermal conductivity of $T^{0.85}$ over the range of this investigation $(8,9)$. Accordingly, Equation (5) can be rearranged as follows in terms of properties evaluated at the surface temperature and the coefficient $A_{b}$ and exponent $m_{b}$, obtained in terms of properties evaluated at the bulk temperature.

$$
\begin{aligned}
\frac{h D}{k_{a}}= & A_{b}\left(\frac{\dot{C}_{p} \mu}{k}\right)^{1 / 3} \\
& \cdot\left(\frac{D G}{\mu_{a}}\right)^{0.8}\left(\frac{T_{b}}{T_{\mathrm{a}}}\right)^{0.31+m_{b}}
\end{aligned}
$$

The net coefficient in Equation (8) is obviously the same as in Equation (5) and the net exponent is increased by $0.85-(0.8)(0.68)=0.31$. These values are in reasonable agreement with the results shown in Table 2 in which the actual variation in properties rather than the power representation was utilized. The correlation obtained in terms of surface temperature is thus equivalent to
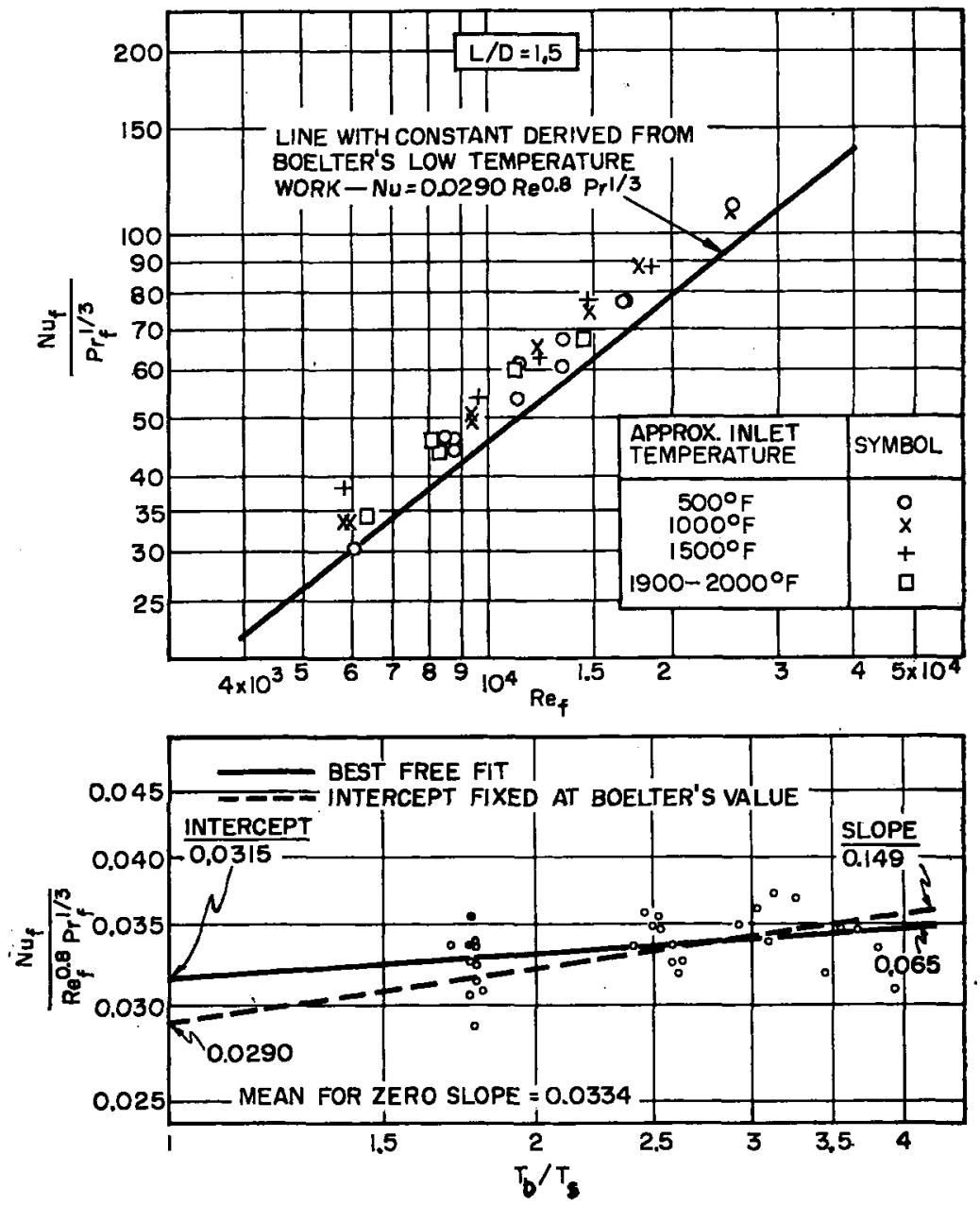

Fig. 6. Correlation of heat transfer data for $L / D=1.5$; properties evaluated at film 1 temperature.

Table 1. Evaluation of Constants in Equation (5), Properties Evaluated at Bulk Trmperature

Best free fit

$\begin{array}{rccc}L / D & h / h_{\infty}(3) & A & m \\ 1.5 & 1.26 & 0.0295 & +0.007 \\ 4.0 & 1.09 & 0.0264 & -0.026 \\ 7.0 & 1.03 & 0.0237 & -0.003 \\ 10.0 & 1.00 & 0.0223 & +0.042\end{array}$

$\begin{array}{llll}10.0 & 1.00 & 0.0223 & +0.042\end{array}$

$\sigma, \%$

6.3

7.8

7.2
6.3
Fixed $A$

$\begin{array}{cc}A & m \\ 0.0290 & +0.027 \\ 0.0251 & +0.026\end{array}$

$+0.026$

$0.0237+0.002$

$0.0230+0.005$

$\begin{array}{rc} & m= \\ \sigma, \% & A \\ 7.8 & 0.0297 \\ 10.2 & 0.0257 \\ 7.8 & 0.0236 \\ 6.8 & 0.0231\end{array}$

$m=0$

Table 2. Evaluation of Constants in Equation (5) for Different Reference Temperatures

Best free fit

Reference temperature

1.5

10.0 Bulk

\section{A}

0.0295

0.0315

Surface

Bulk

Film
0.0288

0.0223

0.0228 $m$

0.007

0.065

0.337

0.042

0.135
Fixed $A$

$$
\text { A }
$$

0.0290

0.0290

0.0290

0.0230

0.0230 $\sigma, \%$

7.8

7.8

7.2 
that obtained in terms of bulk temperatures, insofar as the variation of properties can be represented as a power of the absolute temperature.

There is no such equivalence for the correlation obtained in terms of the film temperature. With a free fit the coefficient $A$ is strikingly higher; i.e., the correlation does not extrapolate satisfactorily to the low-temperature results of Boelter, et al. (3). With $m=0$ and with a fixed intercept to force extrapolation to the low temperature results, a poor representation is obtained, as illustrated in Figures 6 and 7. Coefficients which differ about $13 \%$ from those of Boelter are obtained. This difference appears to be greater than the uncertainties in the data of Boelter and of this investigation and a null hypothesis test indicates that it is statistically significant. The correlation based on bulk temperature is therefore recommended unless a temperature ratio is included. Even if a temperature ratio with the corresponding exponent indicated in Table 2 is included in the correlation, the bulk or surface temperature appears to be a more satisfactory reference temperature than the film temperature.

The mean and probable error for all thirty data points at each of the four stations are compared with the correlation of Boelter, et al. in Figure 8. The agreement is excellent even though dividing the ordinate by $\left(D G / \mu_{b}\right)^{0.8}$ accentuates the deviations, as is apparent in the two portions of Figure 4. It should be noted that Figure 8 is general for all flow rates and air temperatures insofar as Equation (7) holds; whereas $T_{b} / T_{\mathrm{s}}$ becomes a parameter when $h / h_{\infty}$ or $\left(h D / k_{b}\right)$ / $\left(h D / k_{b}\right)_{\infty}$ is plotted vs. $L / D$.

The local heat transfer coefficient itself at $L / D=1.5$ is plotted in Figure 9 to emphasize the very real increase which takes place with increasing air temperature. Since $\left(h D / k_{b}\right) /\left(D G / \mu_{b}\right)^{0.8}$ does not increase with the bulk air temperature, $h$ must be approximately proportional to $k_{b} / \mu_{b}{ }^{0.8}$ and hence to $T_{\mathrm{b}}{ }^{0.31}$.

All previous investigators have found that by $L / D=10.0, h D / k$ attains essentially its asymptotic value for long tubes with constant wall temperature. Hence the results obtained and conclusions drawn for $L / D=10.0$ appear to be applicable for a mean $h D / k$ in a long tube.

The prediction of Deissler (6) that the data for cooling could be generalized in terms of the properties at the film temperature or at $0.4 T_{b}+0.6 T_{s}$ does not appear to be compatible with the results of this investigation. However, as emphasized by Deissler, this prediction was based on the assumption that both the viscosity and the thermal conductivity were proportional to $T^{0.68}$. Recalculation of the experimental $h D / k$ in terms of

$$
k=k_{a}\left(T / T_{a}\right)^{0.68}
$$

rather than in terms of the values given
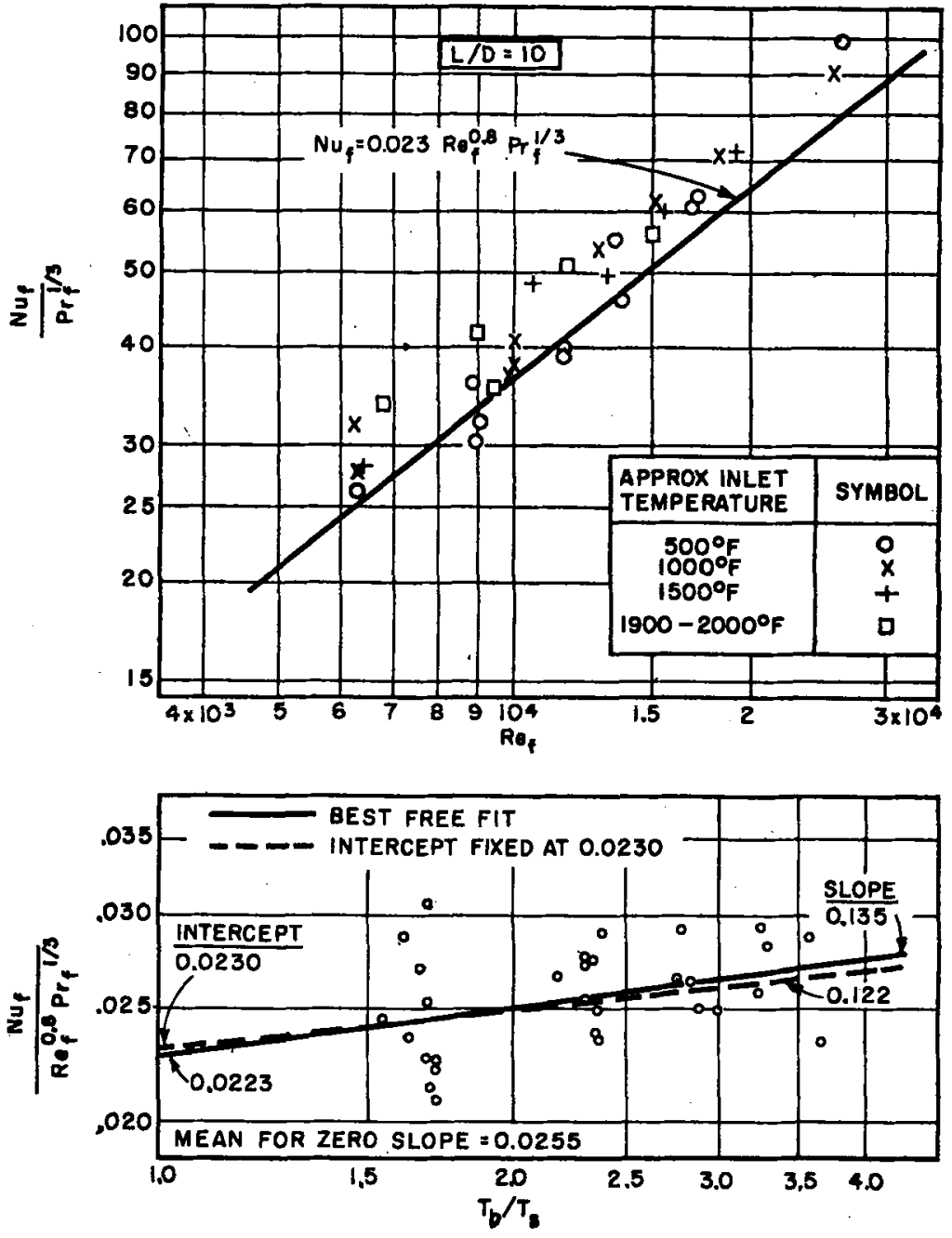

Fig. 7. Correlation of heat transfer data for $L / D=10$; properties evaluated at film temperature.

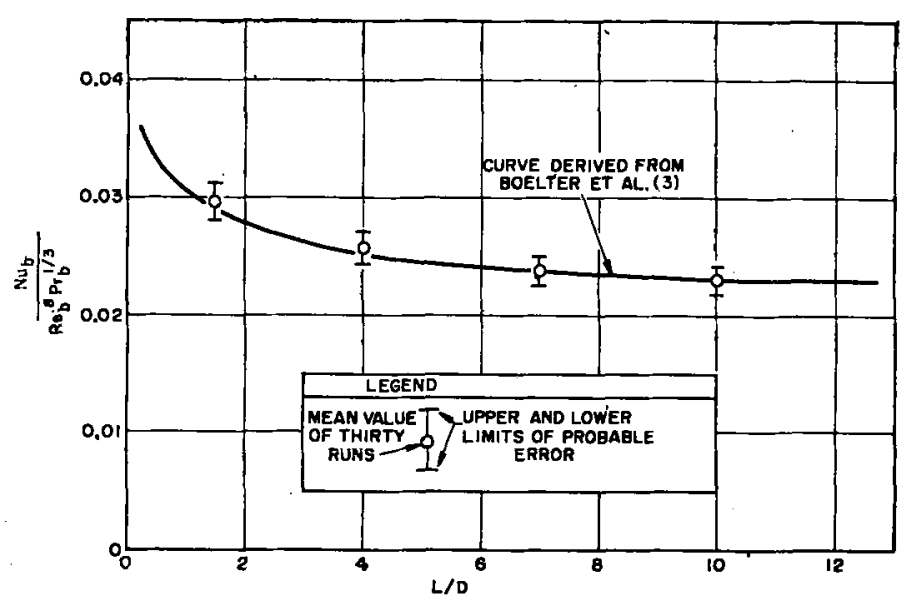

Fig. 8. Summary of local heat transfer rate data for high air temperatures.

by Keenan and Kaye (10) was found to yield values of $h D / k$ in excellent agreement with the predictions of Deissler. This emphasizes the dependence of the correlations and the conclusions of this investigation upon the validity of current values for the physical properties.

The results of this investigation for cooling air $\left(T_{b} / T_{a}>1\right)$ are compared with those of Humble, et al. (5) for heating air $\left(T_{b} / T_{a}<1\right)$ in Figure 10 . The lines represent the correlations obtained with the properties evaluated at the bulk, film, and surface temperatures. The discontinuity in the slope of the lines at $T_{b} / T_{o}=1.0$ is undoubtedly an artificiality resulting from separate correlation of the data for heating and cooling, 
but it does indicate that a power function of the temperature ratio is inadequate to represent the effect of property variation for both heating and cooling of gases in tubes, as contrasted with the success of Douglas and Churchill (12) for the flow of gas over cylinders.

\section{CONCLUSIONS}

The local and the over-all rate of heat extraction from air in turbulent flow in tubes can be predicted from previous correlations for low-temperature differences provided that the viscosity and the thermal conductivity are evaluated at the bulk temperature. An equivalent but less convenient correlation can be obtained by evaluation of these properties at the surface temperature and inclusion of $\left(T_{b} / T_{s}\right)^{0.33}$ as a factor in the correlation. These conclusions are dependent upon the validity of current values for the thermal conductivity and viscosity of air. Although this investigation was limited to air, similar results are to be expected for other gases for which the temperature dependence of physical properties parallels that of air. Previous investigations of gaseous convection appear to justify the generalized form in which the data are correlated.

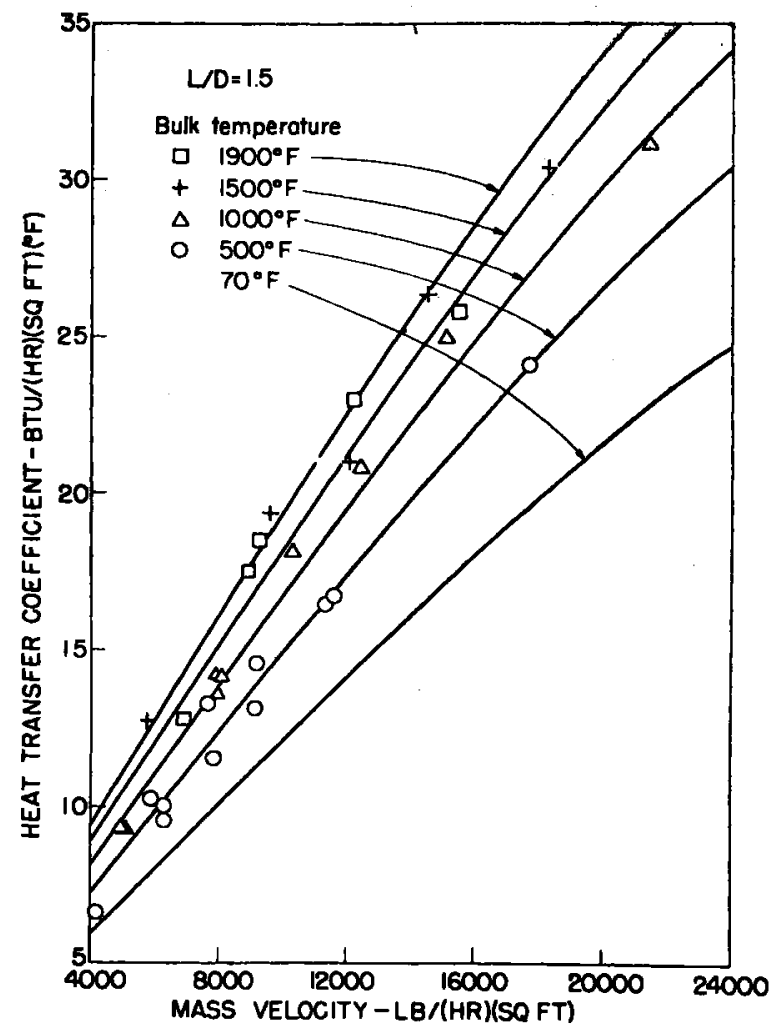

Fig. 9. Local heat transfer coefficients at $L / D=1.5$.

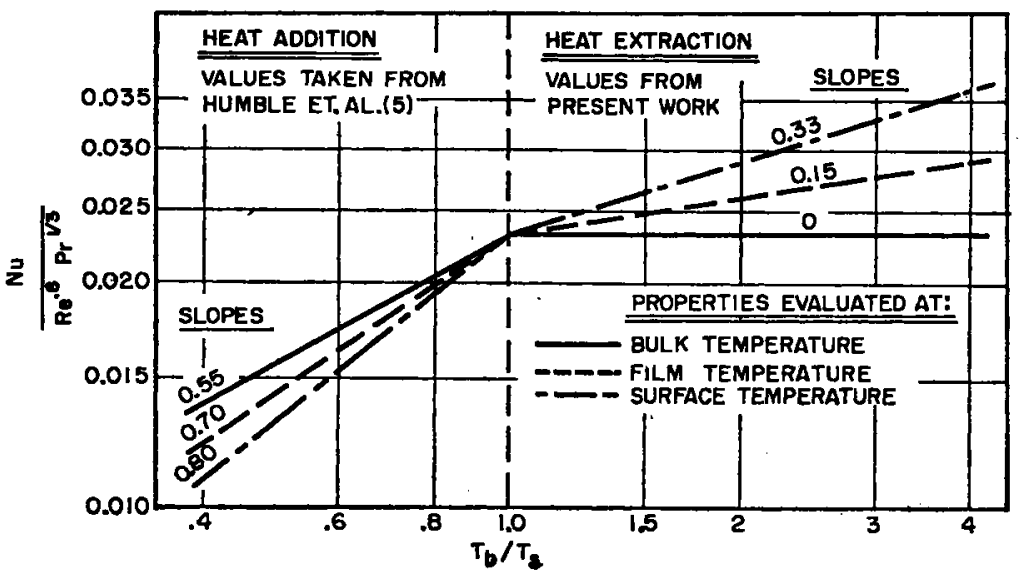

Fig. 10. The effect of temperature level on heating and cooling.
The results are in contrast with correlations for heat addition in which the ratio of the surface to the bulk temperature has been found to be a parameter no matter which single temperature is chosen for evaluation of the gas properties.

\section{NOTATION}

$A=$ coefficient

$C_{b}=$ heat capacity, B.t.u. $/(\mathrm{lb}).\left({ }^{\circ} \mathrm{F}.\right)$

$D=$ diameter, $\mathrm{ft}$.

$G=$ mass velocity, lb./(hr.) (sq. ft.)

$h=$ heat transfer coefficient, B.t.u./ (hr.) (sq. ft.) $\left({ }^{\circ} \mathrm{F}\right.$.)

$k=$ thermal conductivity, B.t.u./(hr.) (ft.) $\left({ }^{\circ} \mathrm{F}\right.$.)

$L=$ tube length, $\mathrm{ft}$.

$m=$ exponent

$N u=h D / k$

$\operatorname{Pr}=C_{p} \mu / k$

$q=$ heat flux, B.t.u. $/($ hr.) (sq. ft.)

$r=$ radial distance, $\mathrm{ft}$.

$R e=D G / \mu$

$\mu=$ viscosity, lb. $/(\mathrm{hr}).(\mathrm{ft}$.

$\sigma=$ standard deviation, $\%$

\section{Subscripts}

$a=$ ambient

$b=$ bulk or mixed mean

$m=$ metal

$o$ = outside tube

$r=$ radiant

$s \quad=$ inside surface

$1=$ any position

2 = any position

$\infty=$ asymptotic value as $L / D \rightarrow \infty$

\section{LITERATURE CITED}

1. McAdams, W. H., "Heat Transmission," 3 ed., McGraw-Hill Book Company, Ine., New York (1954).

2. Groeber, Heinrich, Sigmund Erk, and Ulrich Grigull, "Die Grundgesetz der Warmeubertragung," 3 ed., Springer Verlag, Berlin (1955).

3. Boelter, L. M. K., G. Young, and H. W. Iversen, Natl. Advisory Comm. Aeronaut. Tech. Note 1451 (July, 1948).

4. Deissler, R. G., Trans. Am. Soc. Mech. Engrs., 77, 1221 (1957).

5. Humble, L. V., W. H. Lowdermilk, and L. G. Desmon, Natl. Advisory Comm. Aeronaut. Rept. 1020 (1951).

6. Deissler, R. G., Natl. Advisory Comm. Aeronaut. Tech. Note 2242 (December, 1950).

7. Churchill, S. W., Ph.D. thesis, Univ. Mich., Ann Arbor (1952).

8. Zellnik, H. E., Ph.D. thesis, Univ. Mich., Ann Arbor (1956).

9. Hamilton, D. C., and W. R. Morgan, Natl. Advisory Comm. Aeronaut. Tech. Note, 2836 (December, 1952).

10. Keenan, J. H., and G. W. C. Kaye, "Thermodynamic Properties of Air," John Wiley and Sons, New York (1945).

11. Hilsenrath, Joseph, et al., Natl. Bur. Standards Circular 564 (Nov. 1, 1955)

12. Douglas, W. J. M., and S. W. Churchill, Chem. Eng. Progr. Symposium Ser. No. 18 , 52, p. 23 (1956).

Manuscript submitted May, 1957, paper accepted September 9, 1957 